\title{
Potential of Nanoparticles as Permeation Enhancers and Targeted Delivery Options for Skin: Advantages and Disadvantages
}

\author{
This article was published in the following Dove Press journal:
}

Drug Design, Development and Therapy

\author{
Parisa Ghasemiyeh (D) ${ }^{1,2}$ \\ Soliman Mohammadi- \\ Samani (iD) 2,3 \\ 'Department of Clinical Pharmacy, \\ Faculty of Pharmacy, Shiraz University of \\ Medical Sciences, Shiraz, Iran; \\ ${ }^{2}$ Department of Pharmaceutics, Faculty of \\ Pharmacy, Shiraz University of Medical \\ Sciences, Shiraz, Iran; ${ }^{3}$ Center for \\ Nanotechnology in Drug Delivery, \\ Faculty of Pharmacy, Shiraz University of \\ Medical Sciences, Shiraz, Iran
}

\begin{abstract}
The topical route of administration has many advantages for the treatment of various skin disorders as well as cosmeceutical purposes. This route bypasses hepatic firstpass effect and systemic availability of many pharmaceuticals is limited to skin organelles such as hair follicles and so could avoid unwanted adverse reactions and increase the localized therapeutic effect. Despite such attributed advantages of the topical route, the most important challenge is skin barrier characteristics that should be overcome to obtain dermal or trans-dermal drug delivery. Different approaches have been recruited to overcome this barrier. In this review, different types of nanoparticles for skin permeation enhancement and targeted delivery to skin organelles are discussed. The potential mechanisms of each nanocarrier in permeation enhancement and dermal delivery are considered and finally, the most important advantages and disadvantages of each group are summarized.
\end{abstract}

Keywords: nanoparticles, skin permeation, skin organelles, topical drug delivery, advantages, disadvantages

\section{Introduction}

Skin, the largest organ in the human body, has a multilayered and sophisticated structure. It has a protective function against a harsh environment and could regulate body temperature by controlling the amount of water and heat loss from the body. ${ }^{1}$ Furthermore, skin acts as a very strong barrier toward many drugs administered via topical route. Stratum corneum is the strongest barrier in the skin which is most responsible for limiting drug penetration through skin layers. In addition to stratum corneum, drugs must overcome other cellular and molecular barriers such as antimicrobial barrier, Langerhans cells in the epidermis layer, macrophages in the dermis layer, dendritic cells, and enzymatic systems. ${ }^{2}$ Drug molecule fates during skin penetration across stratum corneum are shown in Figure $1 .^{3}$ In recent years, nanoparticles are highly considered as a permeation enhancing strategy to overcome the barrier characteristics of the different layers of the skin. On the other hand, targeting the different skin organelles including pilosebaceous gland, hair follicle and dermis layer for the better management of different local diseases of the skin layers more considered during the last decades.

\section{Skin Structure}

The skin has a multilayered structure that consists of epidermis, dermis, and hypodermis (Figure 2). Epidermis also divided into different layers including
Correspondence: Soliman MohammadiSaman

Tel +987 I 32426070

Fax +987I32424I 26

Emailsmsamani@sums.ac.ir 


\section{Systemic \\ absorption \\ 2. Enzymatic metabolism}

\section{Drug Molecule Fates During Skin Penetration}

\section{Localization in}

\section{dermis-epidermis}

layers
4. Deep penetration into adipose tissues and muscles

Figure I Drug molecule fates during skin penetration across stratum corneum.

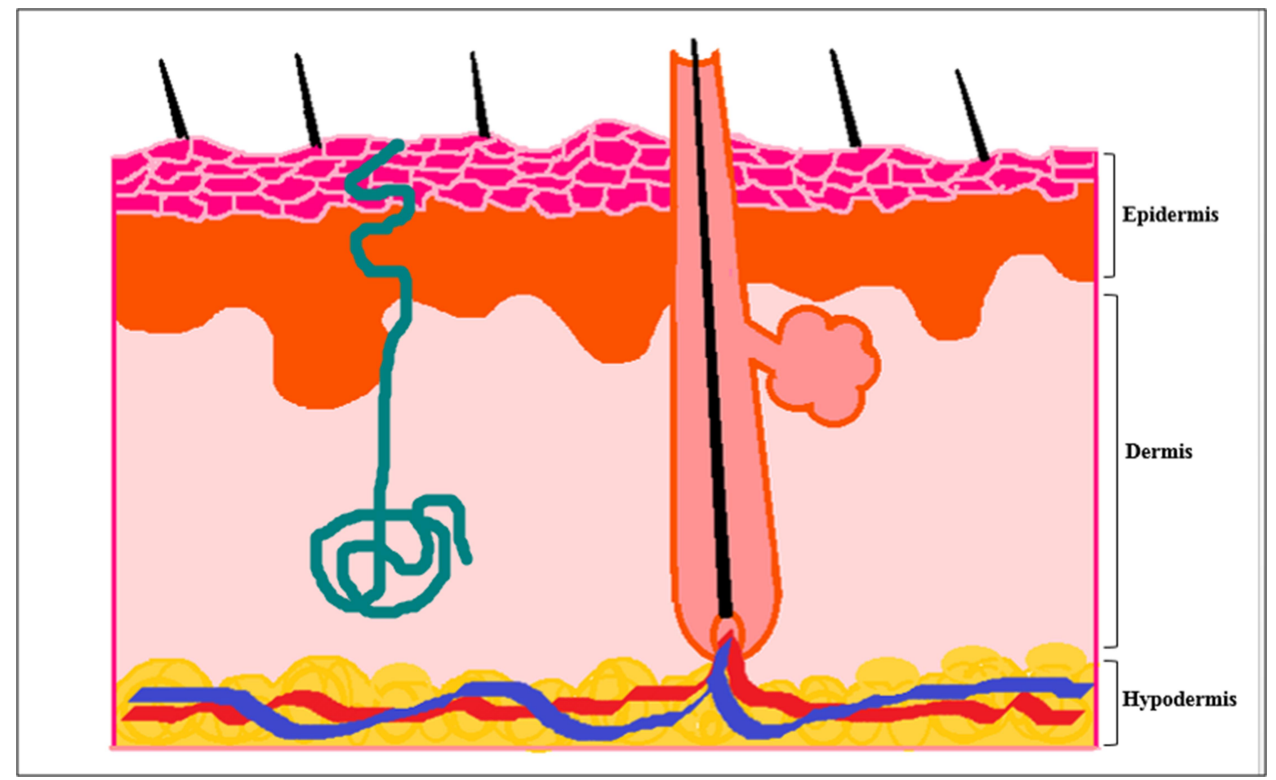

Figure 2 Schematic view of skin layers.

stratum basal, stratum spinosum, stratum granulosum, stratum lucidum, and stratum corneum which is the strongest barrier toward active pharmaceuticals penetration. The epidermis layer has a protective function against harsh environmental conditions. The dermis layer is the thickest layer of the skin and contains sweat glands, hair follicles, pilosebaceous units and blood vessels. Dermis has a nutritive function and could supply blood and oxygen to the skin and clear it from exogenous materials. The hypodermis layer is a subcutaneous fat layer that is responsible for fat storage and controlling the body temperature. ${ }^{2}$ Active pharmaceuticals could pass through the different skin layers by different mechanisms including trans-cellular, intercellular, and trans-appendages. The mechanism of skin permeation is highly affected by physicochemical 
characteristics of active pharmaceuticals and their carriers, such as particle size, particle charge, fluidity, hydrophilicity/lipophilicity, etc.

\section{Skin Appendices \\ Hair Follicles and Pilosebaceous Units}

Hair follicles act as a pore in the skin. So, it would be considered as an important pathway of penetration for drugs that have low permeation via para-cellular or transcellular pathways. Also by specific follicular targeting, many androgenic skin disorders could be managed. Application of targeted delivery strategy via hair follicles and sebaceous glands has the advantages of need to smaller doses of the drug, so, systemic adverse reactions would be decreased. Hair follicles would be considered as delivery route for systemic drug delivery. The most important parameters that affect follicular targeting are particle size ${ }^{4}$ and Fluidity of the nano- or micro-carriers which used in targeted drug delivery. ${ }^{5}$

\section{Sweat Glands}

Sweat glands are the other opening pore to the surface of the skin. Sweat glands are extended from the dermis to subcutaneous and have the thermoregulation function and could excrete body wastes. ${ }^{2}$

In skin pharmacotherapy, there are two important purposes: First is targeted drug delivery to skin organelles such as hair follicles, sweat and sebaceous glands and the second is transdermal drug delivery and skin permeation enhancement. In this review, the effects of different nanocarriers in skin permeation enhancement and targeted drug delivery to skin organelles are discussed. Also, merits and demerits of different types of nanocarriers such as micellar (vesicular) systems and nanoparticulate systems for these purposes are considered. Finally, a comparison between these nanocarriers in drug loading capacity, their potential in skin permeation enhancement, and their compatibility with skin structure are discussed as well. We also focused on the capability of different types of nanocarriers in dose reduction, targeting potential and avoidance of systemic adverse reactions, in comparison to conventionally available formulations.

\section{Methods}

Literature were considered on PubMed, Scopus, Google Scholar, and Web of Science databases using the key search terms skin permeation, nanoparticles, nanoemulsions, solid lipid nanoparticles, nanostructured lipid carriers, liposomes, niosomes, polymeric nanoparticles, and nanocrystals from 1990 until May 2020. In this regard, titles and abstracts of the articles that were related to the subject were considered for further assessment. This search strategy was limited to articles that were published in English. Review and original articles were included in this study. Results of in vitro and in vivo skin permeation studies were included and discussed in this review. Finally, data were categorized according to the types of nanocarriers used to enhance skin permeation and targeted delivery to skin organelles. Advantages and disadvantages of each nanocarriers for this purpose were summarized in Tables.

\section{Nanocarriers and Nanoparticles}

Nanocarriers are defined as colloidal systems with an average diameter of fewer than 500 nanometers. ${ }^{6}$ Novel nanocarriers such as microemulsion, nanoemulsion, liposome, and nanoparticulate carriers were most investigated with the purpose of dermal and transdermal drug delivery. Nanoparticles have many advantages as topical drug delivery systems such as higher drug deposition in the target region, enhanced physicochemical stability of the drugloaded in nanoparticles and sustained and controlled drug delivery from nanoparticulate systems. In the literature, lipid-based nanoparticles such as nanoemulsions, solid lipid nanoparticles (SLNs), nanostructured lipid carriers (NLCs), liposomes, and niosomes were highly considered as topical drug delivery systems. Polymeric nanoparticles, metal nanoparticles, nanocrystals, and nanospheres, as shown in Figure 3., were also investigated to achieve dermal and transdermal drug delivery. ${ }^{7}$ Hair follicles serve as a promising pathway to increase skin penetration both for dermal and transdermal delivery. The average diameter of nanoparticles is the most important parameter which could determine the depth of follicular penetration regardless of the type of nanoparticles. ${ }^{4,7}$ Specific targeting of hair follicles could be an amazing option to treat acne vulgaris, androgenetic alopecia, and hirsutism. Transfollicular drug delivery has the advantages of long-term drug deposition and storage, deep penetration into skin layers, tissue targeting, and increment in cutaneous bioavailability. ${ }^{8}$ Yet, transdermal delivery through hair follicles is associated with many challenges ${ }^{9}$ such as poor physicochemical properties of active pharmaceuticals (solubility, pharmacokinetics, metabolism, compatibility, etc.), transdermal delivery system characteristics (adhesion, permeability, storage, shelf life, etc.), and biological 


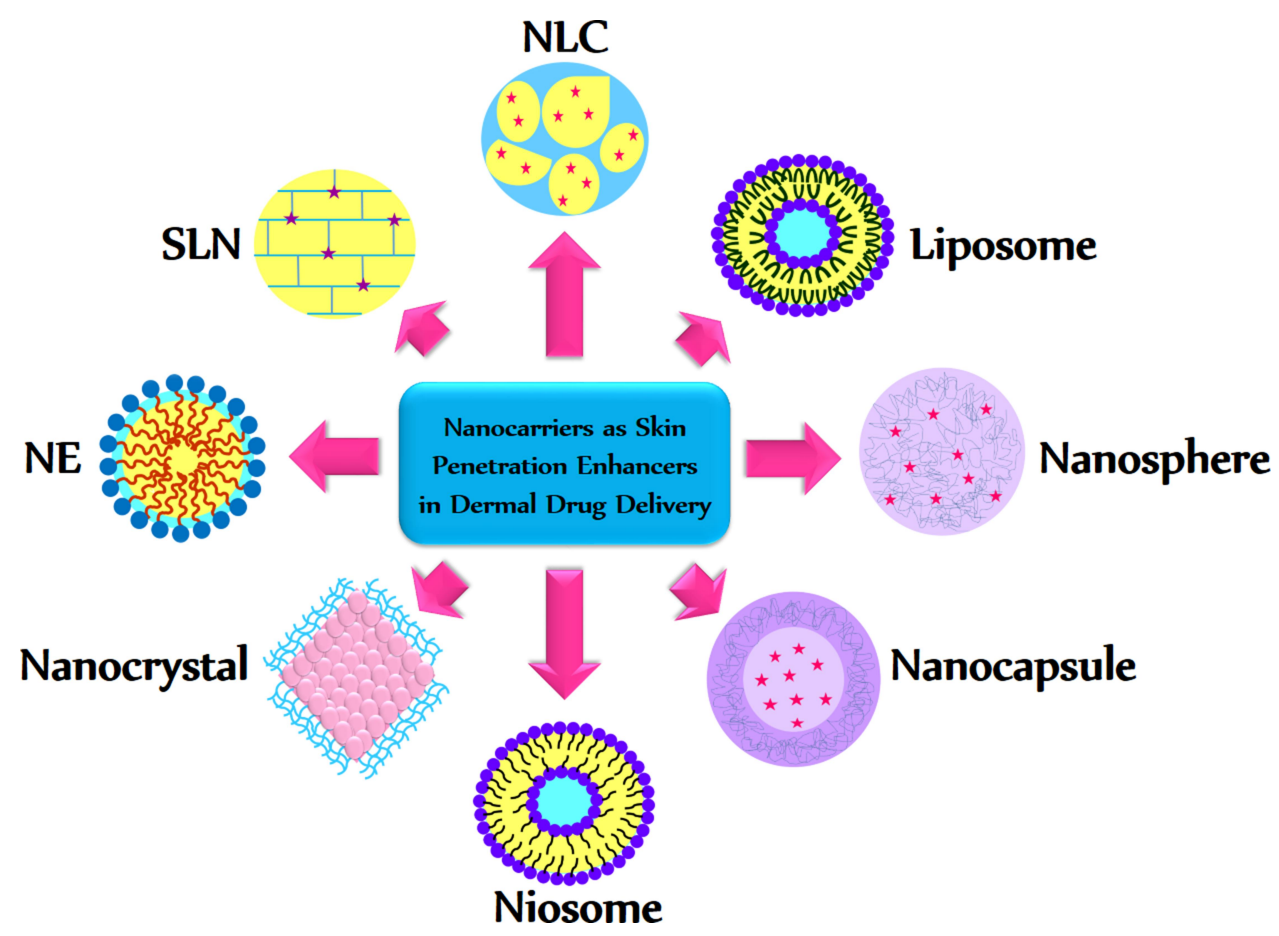

Figure 3 Nanoparticles as novel topical drug delivery system (TDDS) used to improve skin penetration, dermal and transdermal delivery.

factors (site of application and variability in skin permeation) that should be overcome. ${ }^{10}$

\section{Nanoemulsions (NEs)}

Nanoemulsions (NEs) are oil in water dispersions with an average diameter of 20 to 200 nanometers which are thermodynamically stable. NEs have the advantages of low toxicity, non-irritancy, and long-term stability as well as being applicable using different routes of administration, specifically in dermal and transdermal drug delivery. ${ }^{11}$ NEs are potential nanocarriers to enhance skin permeation by increasing gradient concentration of active pharmaceuticals, and increase skin permeation because of the presence of surfactants, as permeation enhancers in their structures. Upon dermal administration of paclitaxelloaded NE, as an example of lipophilic and high MW drug in psoriasis, excellent targeted delivery to dermis and epidermis and also minimal systemic absorption were observed. As reported, NE maintained a high localized drug concentration in skin layers for up to 48 hours. ${ }^{3}$

NEs are also promising nanocarriers for transdermal drug delivery to systemic circulation with the advantages of controlled and extended drug release, ease of selfadministration, transparent nature and smooth skin feeling and absence of gastrointestinal adverse effects. ${ }^{12}$ NEs with submicron particle size could easily penetrate through skin pores and reach the systemic circulation. Caffeine (an example of a hydrophilic drug)-loaded NE has shown a significant increase in skin permeation, compared to conventional caffeine solutions. Naproxen (an example of a lipophilic drug) -loaded NE also exhibited a greater skin penetration in comparison with free drugs administration. ${ }^{13} \mathrm{NE}$ containing penetration enhancers could increase skin penetration through different mechanisms such as increment of drug solubility in carrier, specific carrier uptake into the stratum corneum and fluidization, alteration and dissolution of the stratum corneum lipids. ${ }^{13}$ NEs with oils and surfactants in their formulations are highly capable of increasing transdermal delivery of both hydrophilic and lipophilic drugs. NEs are amazing nanoparticles for the transdermal delivery of active pharmaceuticals to increase drug bioavailability and therapeutic efficacy. ${ }^{11}$ Some pros and cons of NEs as nanocarriers in topical drug delivery systems are listed in Table 1.

Positively charged NEs are potential nanocarriers to enhance skin penetration through the interaction with negatively charged stratum corneum. ${ }^{14}$ To investigate this theory, in vitro release and ex vivo skin penetration studies of prednicarbate-loaded both positively and negatively charged NEs were assessed. Results revealed that drug release from negatively charged NEs was significantly 
Table I Nanoemulsions (NEs) as Nanocarriers in Topical Drug Delivery Systems; Advantages and Disadvantages

\begin{tabular}{|c|c|}
\hline Advantages $12,13,18$ & Disadvantages \\
\hline $\begin{array}{l}\text { - Having high surface area and free energy with the potential of effective dermal } \\
\text { - Absence of instability problems such as creaming, flocculation, sedimentation, } \\
\text { etc. } \\
\text { - Low-toxicity and low-irritancy } \\
\text { - Low interfacial tension and good wetting properties } \\
\text { - Versatility in NE formulations such as cream, spray, patch, liquid, etc. } \\
\text { - Controlled drug delivery of cosmeceuticals } \\
\text { - Suitable for dermal delivery of lipophilic drugs } \\
\text { - Increment of skin penetration of many active pharmaceuticals } \\
\text { - Reduction in transepidermal water loss (TEWL) } \\
\text { - Good patient compliance and comfortable skin feeling due to their transparent } \\
\text { - Improvement in solubilization capacity of active pharmaceuticals } \\
\text { - Increment of the bioavailability of practically insoluble drugs } \\
\text { - High capacity to entrap large amounts of hydrophobic drugs } \\
\text { - Mutual compatibility } \\
\text { - Drug protection against enzymatic and hydrolytic degradation } \\
\text { - Uniform deposition because of low surface and interfacial tension } \\
\text { - Enhancement of storage stability } \\
\text { - Meta-stability and fragility in nature }\end{array}$ & $\begin{array}{l}\text { - Disruption of stratum corneum lipids integrity due to the } \\
\text { presence of permeation enhancers }{ }^{13} \\
\text { - Need for large amounts of surfactants and/or energy for } \\
\text { nanoemulsion preparation }{ }^{12} \\
\text { - The necessity of special and expensive techniques for } \\
\text { their preparation } \\
\text { - Limited information about the mechanism of NE pre- } \\
\text { paration and the effects of surfactants and co- } \\
\text { surfactants on nanodroplet formation } \\
\text { - Limited information about the effect of interfacial chem- } \\
\text { istry on NE fabrication }{ }^{12} \\
\text { - The difficulty of organic solvent removal from these } \\
\text { formulations. }\end{array}$ \\
\hline
\end{tabular}

higher than from positively charged NEs, but amazingly, positively charged NEs had a significantly higher skin penetration in comparison with negatively charged counterparts. These results suggesting that better skin penetration enhancement after the application of positively charged NEs would be the outcome of better interaction of the negatively charged components of corneocytes with positively charged NEs. ${ }^{14,15}$ Another recent publication reported that quaternized chitosan-coated NEs with a positive charged structure would be a promising transdermal delivery system for lipophilic active agents. The higher positive charge of this type of nanocarrier could induce higher electrostatic interactions with the negative charge of skin bioactive components and also electrostatic deposition in skin layers. $^{16}$

Self-assembled multiple nanoemulsions such as w/o/w nanoemulsions have the advantages of modified drug release, gradual permeation flux through skin layers (zeroorder pharmacokinetic), and longer deposition in the skin target area, so a superior clinical response would be obtained via these types of topical drug delivery systems. ${ }^{17}$

\section{Solid Lipid Nanoparticles (SLNs)}

Solid lipid nanoparticles (SLNs) are the first generation of lipid-based nanocarriers formed from solid lipids and emulsifiers. They are fabricated from lipids that are completely solid at room temperature. ${ }^{19}$ SLNs have size ranges between 40 and $1000 \mathrm{~nm}$. Lipid nanoparticles are known as safe drug delivery systems due to several reasons including biocompatibility, biodegradability, and low toxicity. ${ }^{20}$ SLNs, topical drug delivery systems, have the potential of adhesiveness and occlusive properties which enable them to fabricate a homogenous and uniform layer on the stratum corneum and increase residence time and enhance skin penetration by interacting with skin layers and changing its barrier properties. ${ }^{21}$ Topical drug delivery via lipid nanoparticles could obtain high drug deposition in specific targeted areas like hair follicles, sebaceous glands, and sweat glands to minimize systemic adverse reactions. $^{22}$ Previous research also revealed that SLNs could significantly enhance dermal uptake of active pharmaceuticals in comparison to nanoemulsions and simple oil in water creams due to the SLNs occlusive properties and film formation on the surface of the skin. ${ }^{22}$ A reported study showed that SLNs could significantly increase the amount and depth of cyclosporine A and calcipotriol skin penetration, compared to free drugs for psoriasis treatment. Also, in vivo studies revealed that cyclosporine A and calcipotriol-loaded lipid nanoparticles had the maximum skin inflammation reduction, better lesion 
improvement, and lower psoriatic score in comparison with free drugs. ${ }^{21}$ Benzoyl peroxide-loaded SLN showed a higher drug deposition in skin organelles, lower skin irritation, sustained drug release, lower drug absorption to the systemic circulation, and reduced adverse effects in comparison with available marketed formulations. ${ }^{23}$ Lipid nanoparticles are promising carriers for the topical delivery of lipophilic drugs with high $\log \mathrm{P}$ values (log $\mathrm{P}>3$ ) and large molecular weights. Because of their lipidic nature, SLNs have higher entrapment efficiency and penetrate deeply through skin layers. The selection of lipid mixture and surfactants plays an important role in drug encapsulation within the lipid nanoparticles, especially SLNs (with perfect crystalline structure) in preventing drug expulsion during preparation and storage condition. So, the solubility of active pharmaceuticals in the lipid mixture should be evaluated before nanoparticle fabrication. $^{21}$ As previously stated, a lipid mixture of the formulation and surfactants has profound effects on drug loading and SLNs size. ${ }^{20}$ Nanoparticles size could highly affect the amounts and depth of drug penetration through skin layers and targeted drug delivery to hair follicles. The most important disadvantage of SLNs as topical nanocarriers is their perfect crystalline structure which results in lower drug loading and higher burst effect. To overcome this limitation, the addition of second solid lipid component (complex triglycerides such as Softisan 378) to the solid lipid matrix (solid wax such as cetyl palmitate) reportedly showed better physical stability, higher drug encapsulation efficiency and better extended-release capability. $^{24}$ Lipid-based nanoparticulate systems are capable of increasing skin penetration of active pharmaceuticals because of their small particle size and close contact with stratum corneum. They can provide a dense film on the surface of the skin which has an occlusive effect and increase skin hydration. Another reason for skin permeation enhancement of lipid nanoparticles is the presence of surfactants in their formulations which can fluidize or loosen the stratum corneum layer. In the skin permeation process, initially, the drug should be released from the nanoparticles and then it could be either partitioned in or uptaken by the skin. ${ }^{25}$ SLNs could also be used in cosmeceuticals, eg, in a recent study the anti-wrinkle effect of retinyl palmitate-loaded SLNs has been evaluated, and the results revealed that this formulation could increase skin penetration and protect skin from ultraviolet radiation degradation and can serve as a promising anti-aging cosmetic. ${ }^{19}$ So, SLNs could be promising nanocarriers for the treatment of dermatologic disorders, such as acne, psoriasis, alopecia, hirsutism, ichthyosis, etc. because of their amazing results in controlled drug release, enhanced skin penetration, and dermal targeting potential. Some advantages and disadvantages of SLNs as nanocarriers in topical drug delivery systems are listed in Table 2.

\section{Nanostructured Lipid Carriers (NLCs)}

NLCs are the second generation of lipid nanoparticles, formed from the mixture of solid and liquid lipids. ${ }^{19}$ Liquid lipids used in NLCs preparation are oleic acid, ${ }^{40}$ Miglyol, ${ }^{40}$ triolein, ${ }^{4,20}$ Capryol PGMC, copaiba oil, sweet almond oil, sesame oil, ${ }^{41}$ etc. These nanoparticles are promising carriers in pharmaceutical and cosmeceutical delivery including dermal, transdermal, and follicular

Table 2 Advantages and Disadvantages of SLNs as Nanocarriers in Topical Drug Delivery Systems

\begin{tabular}{|c|c|}
\hline Advantages & Disadvantages \\
\hline $\begin{array}{l}\text { - Enhancing the amount and depth of skin penetration }{ }^{26} \\
\text { - Occlusive properties }{ }^{26} \\
\text { - Biocompatibility and skin tolerability }{ }^{24} \\
\text { - Low toxic (generally considered as safe compounds) }{ }^{27,28} \\
\text { - Reducing skin irritation }{ }^{27} \\
\text { - Sustained drug release possibility } \\
\text { - Improvement of direct penetration through stratum corneum }{ }^{27,30} \\
\text { - Active pharmaceutical protection against environmental conditions }{ }^{31} \\
\text { - Ease of process scale-up } \\
\text { - Specific follicular drug delivery } \\
\text { - Enhancing water solubility of drugs } \\
\text { - Avoidance of systemic absorption of active pharmaceuticals }{ }^{33} \\
\text { - Well-tolerated and biodegradable composition } \\
\text { - }{ }^{36}\end{array}$ & $\begin{array}{l}\text { - Drug expelling during preparation and storage due to the per- } \\
\text { - Lect crystalline nature of some solid lipids } s^{31,37} \\
\text { - Low Physical stability } \\
\text { - Initial burst drug release followed by controlled release }{ }^{24} \\
\text { - Limitation in transdermal drug delivery } \\
\text { - Higher viscosity and so lower skin penetration than } \mathrm{NLCs}^{25} \\
\text { - Limited epidermal targeting effect } \\
\text { - The possibility of polymorphic transition } \\
{ }^{37}\end{array}$ \\
\hline
\end{tabular}


purposes. The use of such nanocarriers has many advantages such as drug protection, controlled drug release, enhanced drug bioavailability, and improved skin penetration and deposition. One of the mechanisms for skin penetration enhancement by NLCs is their occlusive properties and small particle size that induces better nanoparticles adhesion to stratum corneum and increment of the amount and depth of skin penetration of loaded molecules through extending the specific surface area. Lipid nanoparticles are capable of interacting with lipid bilayer membranes and causing lipid rearrangement which can improve the penetration of encapsulated drug molecules. NLCs can also increase skin hydration by film formation at stratum corneum surface and avoiding trans-epidermal water loss. ${ }^{19,42}$ Another promising application of lipid nanoparticles, especially NLCs, is follicular delivery of active pharmaceuticals for the treatment of androgenic skin disorders such as acne, hirsutism, and alopecia. The most important factor influencing the amount and depth of follicular delivery is nanoparticles size ${ }^{20}$ ie, smaller particles can reach systemic circulation, while larger ones remain on the surface of the stratum corneum and nanoparticles with intermediate size can highly be deposited in hair follicles and sebaceous glands. ${ }^{4,43}$ In cosmeceutical applications, NLCs showed better results than SLNs, for example, octyl methoxycinnamate (OMC)-loaded NLCs exhibited a better UV protection than OMC-loaded SLNs which might be due to higher solubility of OMC in liquid lipids of NLCs, which reportedly have a higher capability in avoidance of OMC photodegradation and lipid peroxidation. ${ }^{19}$ So, NLCs can serve as promising nanocarriers for sunscreens which minimize percutaneous absorption and enhance subcutaneous accumulation because of their higher tendency to the keratin. Another application is in wound healing where NLCs are capable of increasing residence time in the local wounds, thereby, reducing the healing time process. Some advantages and disadvantages attributed to NLCs as nanocarriers in topical drug delivery systems are listed in Table 3.

\section{Liposomes}

Liposomes consist of one or more lipid bilayers with an embedded aqueous phase in their structure and form a vesicle. Liposomes usually comprise phospholipids and cholesterol. Liposomes as vesicular nanocarriers have many advantages for topical drug delivery such as controlled drug release, localized drug deposition in skin layers, reduced systemic absorption, and less drug side effects. Localized skin deposition of active pharmaceuticals loaded liposomes was proved by lower serum concentration and urine excretion of the drug. ${ }^{47}$ The deposition efficiency of drug-loaded liposome is highly affected by the types and compositions of the liposomes, particle size, lamellarity, fluidity, occlusive properties ${ }^{48}$ and also depends on the methods of liposome preparation. It was reported that SCL (stratum corneum lipid) liposomes had a higher skin deposition than phospholipid liposomes and phospholipid liposomes had a higher deposition than $\mathrm{o} / \mathrm{w}$ emulsion and hydro-alcoholic drug solutions. ${ }^{49}$ The other advantage of liposomes as topical

Table 3 Advantages and Disadvantages of NLCs as Nanocarriers in Topical Drug Delivery Systems

\begin{tabular}{|c|c|}
\hline Advantages & Disadvantages \\
\hline $\begin{array}{l}\text { - Higher drug loading capacity and entrapment efficiency } \\
\text { - Controlled drug release and prevention of initial burst release } \\
\text { - Prevention of drug expulsion during preparation and storage } \\
\text { - Enhancing skin permeation of active pharmaceuticals }{ }^{25} \\
\text { - Acting as a drug reservoir in the dermis for prolonged drug release }{ }^{25} \\
\text { - More occlusive properties than } \mathrm{SLNs}^{25,44} \\
\text { - More drug fluxes through the skin than } \mathrm{SLNs}^{25} \text { and enhanced cutaneous } \\
\text { bioavailability } \\
\text { - Enhancing water solubility of drugs } \\
\text { - Follicular delivery of active pharmaceuticals in acne vulgaris, hirsutism, and } \\
\text { - Lowecia } \\
\text { - Enhancing the physicochemical stability of loaded active pharmaceuticals } \\
\text { - Skin hydration properties } \\
\text { - Reduction of intrinsic cytotoxicity }\end{array}$ & $\begin{array}{l}\text { - Lower viscosity than SLNs which causes shorter skin resi- } \\
\text { dence time } \\
\text { - Promising results just for local applications, not transdermal } \\
\text { use }^{19} \\
\text { - Lower occlusive effect than } \mathrm{SLNs}^{46}\end{array}$ \\
\hline
\end{tabular}


drug delivery systems is their potential follicular targeting. ${ }^{50}$ Liposomes are also capable of providing transdermal drug delivery and recent reports show that deformable vesicles (called transfersome) are a better choice than conventional liposomes for transdermal delivery purposes. $^{47}$ The addition of surfactants to liposome composition results in more flexible and elastic lipid bilayers which can in turn significantly increase drug permeation through the epidermis and transdermal drug delivery. Addition of ethanol to liposome composition (so-called ethosome) can also increase the vesicle's flexibility and so increase skin permeation efficiency. ${ }^{47}$ Nanotechnology could also be recruited to treat some challenging disorders such as skin cancer. In this regard, sulforaphane-loaded ultra-deformable vesicles have been studied. Using this novel topical formulation would be promising in skin cancer management with the advantage of dose reduction in comparison with systemic route of administration and so lower adverse reactions would be predictable. Also, this route of administration accompanied by higher patient compliance. Ultra-deformable and elastic liposomes with an average particle size of below $300 \mathrm{~nm}$ have been also studied in the management of skin cancers and cutaneous inflammatory disorders. ${ }^{51}$ These types of nanocarriers have the advantage of long-term stability and modified drug release kinetics. Although the topical route of administration has many drawbacks in skin drug delivery because of the limitation of skin permeation and stability concerns, ${ }^{52}$ a rational selection of suitable nanocarriers according to physicochemical properties of active pharmaceuticals led to preparation of successful delivery system. Paclitaxel-loaded ethosome has been studied as a potential therapy for squamous cell carcinoma. Results revealed that this topical drug delivery system in comparison with the free drug could enhance skin permeation through the stratum corneum layer and improve its anti-proliferative activity which could result in better therapeutic responses in squamous cell carcinoma cases. ${ }^{53}$ Five different possible mechanisms for liposomal skin permeation have been proposed: the first: free drug mechanism, ie, the drug could independently pass the skin barrier after releasing from its carrier; the second mechanism is permeation enhancing effect in which a liposome component such as lecithin acts as permeation enhancer and could increase transdermal delivery; ${ }^{54}$ the third proposed mechanism is based on vesicle adhesion and fusion with the skin (especially stratum corneum layer) in which liposome could dissolve in stratum corneum and facilitate skin permeation ${ }^{55}$ and in the fourth mechanism, it was proposed that intact liposomes are capable of penetrating through the skin in which drug-loaded liposome or transfersome can penetrate directly within the different skin layers and reach the dermis and act as a drug reservoir there, and finally, the fifth mechanism is based on a trans-appendageal permeation. $^{48}$ In the fourth mechanism, due to the larger size of the liposome in comparison to a drug molecule, systemic absorption could be avoided. ${ }^{47}$ Transfersomes due to the presence of specific surfactants (edge activators) in their structure show more flexibility potential which could facilitate intact skin penetration. There are many parameters influencing the skin permeation efficiency of liposomes such as lipid composition, particle size, surface charge, flexibility and elasticity, and types of the liposomes, etc. ${ }^{56}$ Linoleic acid-loaded ethosome and transfersome have been studied in melasma or hyperpigmentation disorder management, the results revealed that nanocarriers could improve linoleic acid stability and also could penetrate deeply through skin layers and accumulation is dependent on lipid composition and structure. Also, results emphasize the potential efficacy of these two types of nanocarriers as topical drug delivery systems in melasma management. Permeation enhancement related to ethosomes would be a result of the ultra-deformable structure of these vesicular nanocarriers and also due to the presence of ethanol as a penetration enhancer in their formulation. So ethosomes might be better nanocarriers for topical delivery of linoleic acid. ${ }^{57}$ Another study reported that for skin penetration enhancement, rigid liposomes are not suitable topical drug delivery systems, while deformable and elastic vesicular nanoparticles considered as the better delivery vehicles. ${ }^{58}$

Liposomes have two important effects as novel topical drug delivery systems; one is retention and deposition effect (targeted delivery to skin organelles) and the other is enhancement effect (transdermal drug delivery). Liposomes can interact with stratum corneum and disturb its structure. ${ }^{59}$ Liposomes particle size is an important parameter in skin penetration, as previous research reported that smaller liposomes could penetrate deeper into the skin layers and small uni-lamellar vesicles (SUV) could enhance skin penetration more than multilamellar vesicles (MLV). Liposomes with an average diameter of more than $600 \mathrm{~nm}$ were not able to penetrate in deep layers of the skin and mostly remained on the surface of the stratum corneum, liposomes with an average diameter of $300 \mathrm{~nm}$ could penetrate deeper into skin layers 
Table 4 Advantages and Disadvantages of Liposomes as Nanocarriers in Topical Drug Delivery Systems

\begin{tabular}{|c|c|}
\hline Advantages & Disadvantages \\
\hline $\begin{array}{l}\text { - High drug deposition in skin layers and prevention of systemic drug absorp- } \\
\text { tion by acting as a rate-limiting barrier } 47,60 \\
\text { - The ability to transfer both hydrophilic and lipophilic drugs through the } \\
\text { skin }{ }^{48,56} \\
\text { - Non-toxic and non-invasive nature }{ }^{61} \\
\text { - Better dose/effect ratio } \\
\text { - Controlled drug release } \\
\text { - Acting as penetration enhancer } \\
\text { - Further skin penetration enhancement via cationic liposomes }{ }^{48} \\
\text { - The potential of temporally and spatiality controlled drug delivery } \\
63\end{array}$ & $\begin{array}{l}\text { - Stability problems } \mathrm{s}^{47} \\
\text { - Difficulties with scale-up process }{ }^{47} \\
\text { - Variable purity of phospholipids } \\
\text { - High cost } \mathrm{t}^{59} \\
\text { - The rigid surface structure forming extra lipid barrier against } \\
\text { skin penetration }{ }^{55} \\
\text { - Acceleration of systemic absorption of active pharmaceuti- } \\
\text { cals through shunt or follicular pathway and induction of } \\
\text { systemic adverse reactions }{ }^{64}\end{array}$ \\
\hline
\end{tabular}

and liposomes with an average diameter of about $70 \mathrm{~nm}$ are the best option for dermal delivery purposes. ${ }^{59}$ Some advantages and disadvantages of liposomes as nanocarriers in topical drug delivery systems are listed in Table 4.

\section{Niosomes}

Niosomes are the other type of vesicular drug delivery systems with one- or multi-bilayer spheroidal structure. They are formed by the assembly of amphiphilic molecules. Niosomes are nonionic surfactant vesicular drug delivery systems that are introduced as an alternative for conventional liposomes. ${ }^{65}$ Nonionic surfactants are relatively biocompatible and non-toxic and can act as penetration enhancer in topical drug delivery systems. Surfactants with high HLB values are not capable of forming vesicle because of the high hydrophilicity of their molecules, but Spans and Tweens are suitable non-ionic surfactants for noisomes preparation. ${ }^{66}$ One of the mechanisms responsible for skin penetration enhancement of niosomes is a reduction in trans-epidermal water loss (TEWL) and the other is fusion or adsorption of the vesicular drug delivery systems to the skin surface resulting in a higher concentration gradient and so higher skin penetration. Niosomes could also modify the stratum corneum structure and make it looser and more permeable. ${ }^{67}$ Also, non-ionic surfactants, used in niosomes formulations, can function as perfect skin permeation enhancers. ${ }^{59}$ The smaller particle size of niosomes as topical drug delivery systems is also capable of increasing the cutaneous bioavailability of encapsulated drugs. In previous research, it was reported that minoxidil-loaded niosomes could significantly increase skin penetration and cutaneous bioavailability, compared to the control formulation. It was also suggested that particle size and surfactant nature highly affected the amount of skin penetration and bioavailability of encapsulated drugs. ${ }^{65}$ The use of ethanol as an organic solvent in niosomes formulation can increase skin penetration through enhancing vesicle elasticity and fluidization of stratum corneum lipids and also by increasing drug solubility and drug partitioning in stratum corneum. ${ }^{68}$ The presence of ethanol in niosomes formulation can interact with surfactant molecules and reduce the melting point of the vesicles which could increase their fluidity. Also, ethanol is responsible for the reduction of the mean average diameter of niosomes by surface charge modification and steric stabilization. ${ }^{69}$ Another study reported that 5-aminolevulinic acid (ALA)-loaded niosomes could significantly increase skin penetration in comparison to simple aqueous suspension. ${ }^{68}$ In this study, elastic niosomes were compared with classic niosomes (contains Span 60 and cholesterol) for their potential to improve skin penetration, and the results revealed that although elastic niosomes containing dicethyl-phosphate as edge activator, had lower dimensions, their potential to increase skin penetration and drug deposition was less than classic niosomes, which could be explained by the lower percentage of encapsulation efficiency of elastic niosomes in comparison to classic niosomes. So, conventional niosomes were suggested as suitable nanocarriers for ALA delivery to treat skin malignancies by photodynamic therapy. ${ }^{68}$ Niosomes can serve as nanocarriers both for chemical drugs and also peptides and proteins. Components that are used for these two purposes are different; Spans and Tweens are among the most used chemicals in niosomes preparation while poly-oxyethylene ether and diacyl glycerides are mostly used in peptide and protein delivery. These components can also act as penetration enhancers in niosomes formulations. ${ }^{59}$ Types of non-ionic surfactants and the amount of cholesterol in niosomes are important parameters in transdermal delivery. Previous reports indicate that Tweens can enhance trans-dermal delivery more than 
Table 5 Advantages and Disadvantages of Niosomes as Nanocarriers in Topical Drug Delivery Systems

\begin{tabular}{|l|l|}
\hline Advantages & Disadvantages \\
\hline $\begin{array}{l}\text { - Higher physicochemical stability } \\
\text { - Lower price }\end{array}$ & $\begin{array}{l}\text { - Lower trans-dermal permeation in comparison to } \\
\text { liposomes }^{59} \\
\text { - Higher chemical stability }\end{array}$ \\
- Higher skin penetration in comparison to free drug and conventional liposomes & - Difficulties in large-scale production \\
- Enhanced drug deposition and residence time in the epidermis and stratum & - Higher price in comparison to conventional formulations. \\
corneum $^{69,72}$ & Higher surfactant concentrations \\
- Reduced systemic drug absorption and related adverse reactions ${ }^{69}$ & \\
- Improvement in cutaneous bioavailability & \\
- Controlled and sustained drug release & \\
- Reducing trans-epidermal water loss (TEWL) and enhancement of skin & \\
smoothness & \\
- Dr,72 & \\
\hline
\end{tabular}

Spans and lower amounts of cholesterol increase transdermal delivery via niosomes as nanocarriers. ${ }^{59,70}$ The fluidity of the vesicular membrane is an important parameter affecting transdermal drug delivery through niosomes. Essential oils, especially terpenes, are important components in niosomes formulations which can function as penetration enhancers by disruption of the stratum corneum structure. Also, essential oils have the potential of vesicle fluidization and enhancement of the niosomes elasticity which could enhance transdermal drug delivery. Previous research revealed that the addition of essential oil to felodipineloaded niosomes formulation can significantly increase drug flux and this enhancement is highly affected by the amount and types of the added essential oils. Clove oil, lemon oil, and eucalyptus oil can significantly increase transdermal delivery in comparison to plain niosomes and the permeation enhancement ratio was increased with increment in essential oils concentration. ${ }^{71}$ Another study reported that ellagic acid-loaded niosomes showed a significantly higher epidermal and dermal penetration in comparison to the ellagic acid solution. ${ }^{72}$ So, niosomes can promote skin penetration of active pharmaceuticals to deep layers of the skin. The amount of skin penetration enhancement is highly affected by niosomes composition; very hydrophilic surfactants $(\mathrm{HLB}=16)$ can promote drug diffusion through skin layers (trans-dermal delivery) while surfactants with HLB of 9 and 10 can induce drug deposition and increase cutaneous residence time. ${ }^{73}$ Cationic niosomes can also promote further skin penetration enhancement and cutaneous deposition in comparison with anionic or neutral niosomes, possibly due to the negative charge of skin lipids; therefore, additional interactions would be predictable with cationic ones. ${ }^{67}$ Some advantages and disadvantages of niosomes as nanocarriers in topical drug delivery systems are listed in Table 5 .

\section{Nanocrystals}

Nanocrystals are particulate systems that are entirely formed from drugs. Their particle size ranges from 1 to $1000 \mathrm{~nm} .{ }^{77,78}$ Nanocrystals are suspended by stabilizers to avoid particle aggregation. There are three types of stabilizers used for nanocrystal formation; ionic stabilizers such as sodium lauryl sulfate (anionic surfactant) belonging to the first group, the second is non-ionic stabilizers such as Poloxamers and Tweens (non-ionic surfactants) and the third includes polymeric stabilizers such as hydroxyl propyl methylcellulose, polyvinyl alcohol, polyvinyl povidone, hydroxyl propyl cellulose, etc. ${ }^{77}$ The most important advantage of these types of nanopharmaceuticals is the high drug to stabilizer proportions that leading to approximately $100 \%$ drug loading capacity. This advantage makes nanocrystals suitable for drug delivery systems to obtain a high therapeutic concentration in the targeted area. ${ }^{79}$ Nanonization of topical formulations can reduce the particle size (increase the surface area) and increase drug saturation solubility (higher concentration gradient), dissolution rate, drug release rate, surface adhesion, and dermal bioavailability of the drug. There are two available methods for nanocrystals preparation; bottom-up and topdown techniques. ${ }^{80}$ High-pressure homogenization and milling techniques (top-down technologies) are among the most common methods used in nanocrystal and nanosuspension preparation. The final goal of nanonization is the enhancement of skin penetration of poorly watersoluble drugs. Previous research reported that lutein nanocrystals (nanosuspension) amazingly showed higher 
Table 6 Advantages and Disadvantages of Nanocrystals as Topical Drug Delivery Systems

\begin{tabular}{|c|c|}
\hline Advantages & Disadvantages \\
\hline 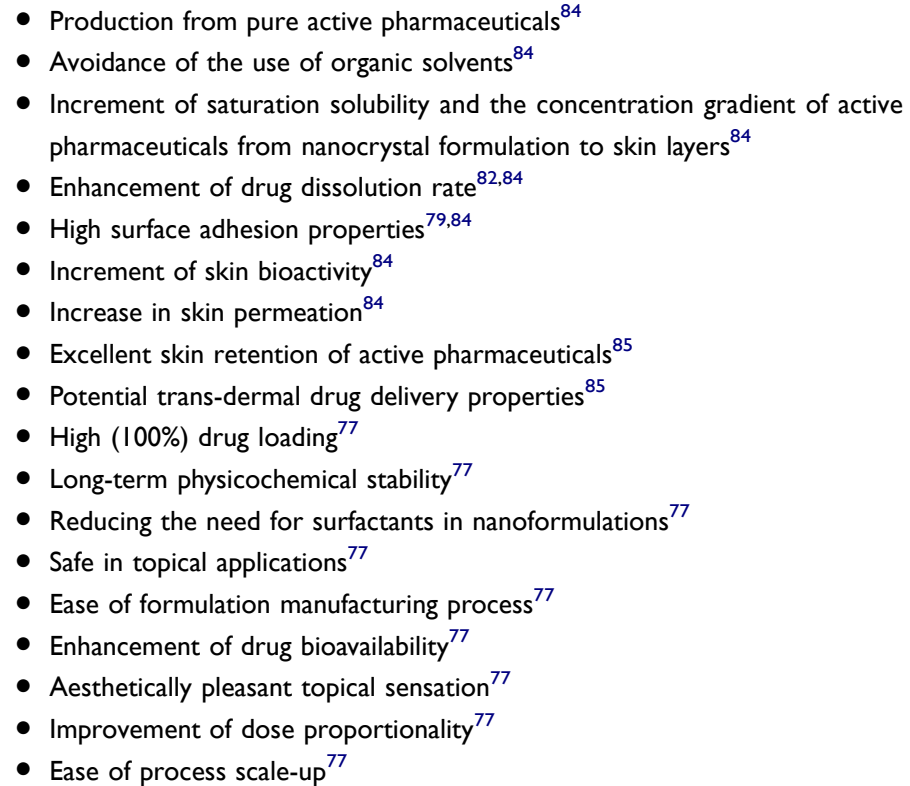 & $\begin{array}{l}\text { - The possibility of agglomeration and flocculation of nanocrystals } \\
\text { - The faster skin penetration rate in comparison to conven- } \\
\text { tional and other topical nanoparticulate formulations }{ }^{82} \\
\text { - The need for more frequent dose administration } \\
\text { - Enhancing the risk of systemic absorption and systemic } \\
\text { adverse reactions } \\
\text { - Not suitable for water-soluble drugs }\end{array}$ \\
\hline
\end{tabular}

saturation solubility in comparison with lutein microcrystals (coarse powder). Also, results revealed that lutein nanocrystals had higher skin penetration. ${ }^{81}$

As nanocrystals can increase the solubility and dissolution rate of poorly water-soluble drugs (especially BCS class II), so they are considered as promising novel topical drug delivery systems for dermal applications. They could improve skin deposition and enhance skin permeation and obtain faster skin penetration in comparison with conventional topical formulations. ${ }^{82}$ Nanocrystals are suitable drug delivery systems for practically insoluble active pharmaceuticals, drugs with limited skin penetration, and less bioactive drugs, but the most important drawback is the need for frequent dose administration. A study reported that dexamethasone nanocrystals enhanced skin penetration more than conventional dexamethasone cream and dexamethasone-loaded ethyl cellulose nanocarriers. Also, the results revealed that in nanocrystal formulation, most of the drug was accumulated in the dermis layer in comparison to conventional or ethyl cellulose nanocarrier formulations in which most of the drug remained in the epidermis. Besides, faster skin permeation was seen with nanocrystal formulation. ${ }^{82}$ The most important mechanism of nanocrystals skin penetration enhancement is the increment of saturation solubility and, therefore, increase in concentration gradient leading to higher passive diffusion of active pharmaceuticals through skin layers. ${ }^{77,83}$ Some advantages and disadvantages of nanocrystals as nanocarriers in topical drug delivery systems are listed in Table 6.

\section{Polymeric Nanoparticles}

Polymeric nanoparticles could be used as potential topical nanocarriers to mask the physicochemical properties of active pharmaceuticals and improve their skin penetration. Polymeric nanoparticles are colloidal nanocarriers with an average diameter of less than $1000 \mathrm{~nm}^{86}$ and they could be divided into two different groups based on their compositions; nanocapsules and nanospheres. The former which contains oil in their formulations have vesicular structure and the latter with no oil in their formulations have matrix type structure. Natural and synthetic polymers have been considered in the topical drug delivery of many active pharmaceuticals. Polymers have the advantages of lowtoxicity and biocompatibility in drug delivery purposes. Also, to improve the physicochemical properties of these polymers, interpenetrating polymeric networks (IPNs) such as hydrogels have been introduced. By using these physically cross-linked network polymers, synergistic improvement in each polymer characteristics would be obtained. Natural polymers such as chitosan have been highly considered as a suitable carrier for drug delivery purposes. The most important advantages of chitosan nanoparticles are biocompatibility, low toxicity, and low immunogenicity. ${ }^{87}$ The most common technique used for 
polymeric nanoparticle preparation is the nanoprecipitation method. Other less useful methods are in situ polymerization, emulsification diffusion, solvent extraction, and salting-out technique. ${ }^{61}$ The most common polymer used in polymeric nanoparticles formulation is poly $(\mathcal{E}-$ caprolactone), a semi-crystalline polymer, with biocompatible and biodegradable properties. Other polymers used for this purpose include chitosan, poly (lactide-coglycolide), poly (E-caprolactone)-block-poly (ethylene glycol), poly (butyl cyanoacrylate), poly (ethyl cyanoacrylate), ethylcellulose, cellulose acetate phthalate and a fatty acid-conjugated poly (vinyl alcohol). ${ }^{88}$ Natural polymeric nanoparticles tend to form hydrogels, so they are suitable nanocarriers for hydrophilic drugs, peptides, proteins, and oligonucleotides. Among natural polymeric nanoparticles, chitosan-based nanocarriers are the most commonly used ones for topical delivery purposes. ${ }^{89}$ Recently, glibenclamide-loaded chitosan nanogels have been reported as suitable topical formulations to treat diabetes with the advantage of enhanced skin permeation. ${ }^{90}$ Hydrogels are the most studied polymeric nanocarriers as drug delivery systems, they have the advantages of higher stability in comparison with nanoemulsions and suspensions. Gelembedded vesicles are topical formulations with the advantage of skin permeation enhancement, improved dermal bioavailability, and better patient compliance. ${ }^{91}$ Synthetic polymeric nanoparticles are more favorable because of high purity, batch-to-batch uniformity, and controlled drug release in comparison to natural polymeric nanoparticles and are suitable nanocarriers both for hydrophilic and lipophilic agents. ${ }^{89}$ Dendritic polymers are synthetic polymers with the symmetric spherical branched arrangement, with a core-shell structure, which could also be used as novel drug delivery systems for dermal purposes. The most commonly used dendritic polymers are poly (amidoamine) and poly (propylene imine) dendrimers. Dendrimers have the advantage of skin permeation enhancement. The most known mechanism of skin permeation enhancement of dendrimers is their interaction with skin lipids and denaturation of keratin proteins which could obtain better trans-cellular permeation of active pharmaceuticals. Also, they are capable of changing the physicochemical properties of active pharmaceuticals and increasing skin partitioning and drug flux. Dermal targeting could be achieved through optimization of particle size, surface charge, and functionalities on dendrimers with limited skin irritation and other adverse reactions. ${ }^{92}$ The main usage of polymeric nanoparticles is for sunscreen delivery because of the advantage of highly lipophilic drug delivery and masking of the physicochemical properties of loaded drug. They also can provide higher sunscreen residence time at the skin surface without further skin penetration. ${ }^{61}$ Dispersion of polymeric nanoparticles in hydrophilic gels can improve their skin penetration. Hydrophilic gels can produce uniform dispersion of nanocarriers and enhance contact time and residence time of active pharmaceuticals at skin surface which promotes higher skin permeation. ${ }^{93}$ Previous research reported that tyrosine-derived nanospheres could efficiently enhance skin permeation of lipophilic drugs ${ }^{94}$ but their action was restricted to upper layers of the skin indicating that polymeric nanoparticles are suitable for topical drug delivery but not for trans-dermal purposes. A previous study reported that to enhance skin permeation and improve physicochemical properties, the hydrophilic gel containing nanospheres are a better carrier; the results revealed that nanosphere gel formulation significantly enhanced skin permeation in comparison to aqueous dispersion nanosphere. ${ }^{93}$ So, the gel formulation of nanospheres could be an amazing nanocarrier for lipophilic agents for dermal delivery purposes. Another study reported that triclosan-loaded cationic nanospheres had higher skin deposition, compared to triclosan solution, and also the results showed that the application of iontophoresis to nanospheres could not provide any further advantages in skin permeation enhancement. ${ }^{95}$ Another advantage of polymeric nanoparticles is the potential of follicular accumulation which was seen with nonbiodegradable polystyrene nanoparticles. Results revealed that follicular accumulation is highly dependent on particle size; ie, the smaller the particle size, the higher the follicular accumulation. ${ }^{96}$ Dexamethasone-loaded Eudragit ${ }^{\circledR}$ RS and ethyl cellulose nanoparticles also exhibited suitable skin adhesion along with the potential of follicular targeted delivery and controlled drug release which could minimize systemic adverse reactions related to dexamethasone. ${ }^{97}$ Some advantages and disadvantages of polymeric nanoparticles as nanocarriers in topical drug delivery systems are listed in Table 7.

\section{Natural-Based Nanoparticles}

Lipid nanoparticles could be prepared using natural lipids such as Illip butter with the potential of skin hydration and Calendula oil with the advantage of anti-inflammatory and healing effects. These natural lipid nanoparticles can be used to encapsulate many active pharmaceuticals to obtain 
Table 7 Advantages and Disadvantages of Polymeric Nanoparticles as Nanocarriers in Topical Drug Delivery Systems

\begin{tabular}{|c|c|}
\hline Advantages & Disadvantages \\
\hline $\begin{array}{l}\text { - Active pharmaceuticals protection against premature degradation } n^{93} \\
\text { - Localized targeted drug delivery and reduced systemic absorption }{ }^{93} \\
\text { - Increment of cutaneous penetration }{ }^{89} \\
\text { - Biocompatible and biodegradable nature } \\
\text { - Controlled drug release by polymer modification techniques } \\
\text { - Avoidance of skin irritation } \\
\text { - The potential of follicular accumulation and trans-follicular drug } \\
\text { - delivery } \\
\text { - Potential of gene delivery } \\
\text { - Non-toxic nature } \\
\text { - Active pharmaceuticals stabilization } \\
\text { - The potential of macromolecules delivery } \\
\text { - Long storage stability }\end{array}$ & $\begin{array}{l}\text { - Not suitable for trans-dermal purposes }{ }^{94} \\
\text { - The necessity of purification processes for natural polymeric } \\
\text { nanoparticles }{ }^{89} \\
\text { - The lack of batch-to-batch uniformity of natural polymeric } \\
\text { nanoparticles }{ }^{89} \\
\text { - The risk of toxicity due to slow polymer degradation rate }\end{array}$ \\
\hline
\end{tabular}

targeted skin delivery. ${ }^{101}$ Another advantage of naturalbased lipid nanoparticles is their lower possible toxicity in comparison to other synthetic ones. An example of these natural lipids is the stearin fractions of fruit kernel which has been studied in topical drug delivery of tretinoin. ${ }^{102}$ So natural-based nanoparticles would be considered as promising nanocarriers for skin delivery and targeting strategy with high efficacy and minimal toxicity concerns.

\section{Commercial Formulations}

Examples of marketed topical novel drug delivery systems have been summarized in Table 8 .

\section{Discussion and Conclusion}

Different types of nanocarriers have been investigated for topical drug delivery in terms of skin permeation enhancement and targeted delivery to skin organelles. A schematic view of different nanocarriers mechanisms in skin permeation enhancement and targeted delivery to skin organelles has been shown in Figure 4. Among them, lipid-based nanocarriers including lipid nanoparticles such as SLNs and NLCs and vesicular nanocarriers such as liposomes, niosomes, and transfersomes were more frequently used and considered. SLNs have the advantage of easy to scale up but they suffer from low loading capacity and entrapment efficiency because of their tendency for recrystallization and also high burst drug release. NLCs are the other type of particulate lipidbased nanocarriers formed from the combination of solid and liquid lipids with the advantage of higher loading capacity and entertainment efficiency and lower burst release. Furthermore, SLNs and NLCs are more suitable for targeted delivery to skin organelles such as hair follicles but they are not the first choice nano-delivery systems for transdermal purposes. The mechanism of skin permeation enhancement of lipid nanoparticles is hydrophobic occlusive film formation. The most important parameter which affects the depth of penetration and location of deposition is SLNs and NLCs particle size. ${ }^{46}$ Vehicular nanocarriers such as liposomes and transfersomes have the advantage of transdermal drug delivery potential. According to a recent research, conventional liposomes are not suitable nanocarriers for transdermal delivery purposes because they can not obtain deep permeation into lower skin layers. Liposomes may rupture during skin permeation because they lack deformability properties which could be seen in transfersomes. ${ }^{46}$ So, transfersomes, with ultra-deformability potential, are considered as better nanocarriers for transdermal purposes in comparison with conventional liposomes. They can deform their structure and pass easily through the stratum corneum layer. The most common skin permeation enhancement mechanism of transfersomes is permeation through the follicular pathway ${ }^{46}$ which also makes them as suitable nano-delivery system for specific follicular targeting for androgenic skin disorders such as acne, hirsutism, and alopecia. It was reported that nanoliposomes with an average diameter of 30 to $40 \mathrm{~nm}$ could induce the highest skin permeation efficiency, compared with lower or smaller nanoliposomes sizes. ${ }^{46}$ The most important advantage of ethosomes is their high efficiency in deep skin permeation of both highly hydrophilic and lipophilic active ingredients because the presence of 
Table 8 A List of Marketed Topical Novel Drug Delivery Systems

\begin{tabular}{|c|c|c|}
\hline Types of Nanocarriers & Marketed Formulation Examples & Reference \\
\hline Lipid nanoparticles & $\begin{array}{l}\text { Cutanova Cream Nano Repair QI0 } \\
\text { Cutanova Cream NanoVital QI0 } \\
\text { SURMER Crème Legère Nano-Protection } \\
\text { NanoLipid Restore CLR } \\
\text { Nanolipid QI0 CLR } \\
\text { IOPE SuperVital } \\
\text { Regenerationscreme Intensiv } \\
\text { Swiss Cellular White Illuminating Eye Essence } \\
\text { Swiss Cellular White Intensive Ampoules } \\
\text { Olivenöl Anti Falten Pflegekonzentrat } \\
\text { Olivenöl Augenpflegebalsam }\end{array}$ & 103 \\
\hline Nanostructured lipid carriers & $\begin{array}{l}\text { NLC Deep Effect Eye Serum } \\
\text { NLC Deep Effect Repair Cream } \\
\text { NLC Deep Effect Reconstruction Cream } \\
\text { NLC Deep Effect Reconstruction Serum }\end{array}$ & 103 \\
\hline Liposomes & $\begin{array}{l}\text { Capture }^{\mathrm{TM}} \text { (anti-aging topical formulation) } \\
\text { Premier }^{\circledR} \text { (anti-aging) } \\
\text { Sinere nanominox-ms (hair tonic) } \\
\text { Diractin }{ }^{\circledR} \text { gel (ketoprofen) } \\
\text { LIPOTAR }^{\text {TM }} \text { S Gel (coal tar and salicylic acid) } \\
\text { Psoriosome } \\
\text { FM } \\
\text { FUNGISOME } \\
\text { Nano-Xir (antioxidant cream) }\end{array}$ & 104 \\
\hline Niosomes & Capture $^{\mathrm{TM}}$ (anti-aging topical formulation) & 104 \\
\hline
\end{tabular}

ethanol in their formulations can function as a permeation enhancer. The synergistic effect of ethanol and phospholipid on skin layers is the possible mechanism of skin permeation enhancement of ethosomes. Ethanol can increase permeation flux by increasing lipid fluidity and decreasing skin lipid density. ${ }^{46}$ Niosomes are more considered as promising nanocarriers for targeted delivery to skin organelles such as hair follicles but not suitable for transdermal purposes. Vesicular nanocarriers in comparison to lipid nanoparticles have the disadvantage of higher prices and difficulties in scale-up processes. Both conventional vesicular systems and lipid nanoparticles, because of their rigid structure, can not penetrate the stratum corneum layer of intact skin but the difference is lipid nanoparticles potential in targeted delivery and deposition in skin organelles and trans-appendageal skin permeation. $^{46}$ In general, previous research concluded that NLCs are better promising nano-delivery systems than vesicular systems such as liposomes and ethosomes in their drug loading capacity and targeted delivery to skin organelles. ${ }^{105}$ Nanoemulsions, organic nanoparticles with liquid core, are the other type of lipid-based nanocarriers with lower loading capacity in comparison to SLNs and NLCs and lower skin permeation potential was reported with nanoemulsions, compared to NLCs. ${ }^{106}$ Positively charged nanoemulsions have been reported as good delivery systems for transdermal delivery purposes because of the presence of permeation enhancers in their structures but this could also disturb skin layers and cause skin irritancy. Although lipid-based nanocarriers are suitable for both hydrophilic and lipophilic drugs, they are considered as better delivery systems for lipophilic drugs due to the maximum loading capacity. For drug delivery of hydrophilic drugs, polymeric nanoparticles and hydrogels are more suggested for their higher encapsulation efficiency. Polymeric nanoparticles are more suitable for targeted delivery to skin organelles and the potential of drug deposition in skin layers but are not suitable nanocarriers for transdermal delivery. Polymeric nanoparticles' potential in the wound healing process was documented and reported. ${ }^{107}$ Among polymeric nanoparticles, those with a positive charge and 


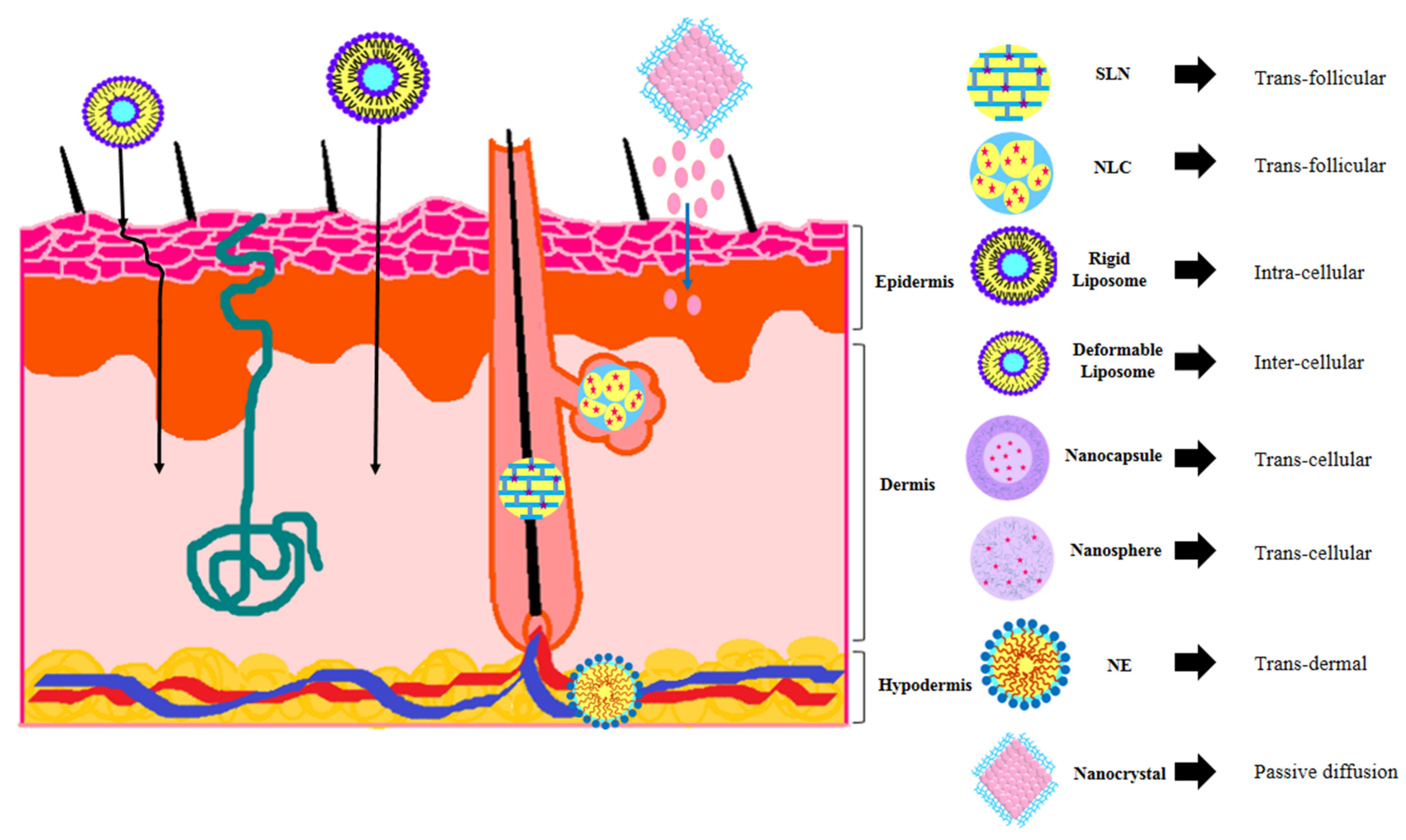

Figure $4 \mathrm{~A}$ schematic view of different nanocarriers mechanisms in skin permeation enhancement and targeted delivery to skin organelles.

average diameter of lower than $50 \mathrm{~nm}$ showed better skin permeation potential. ${ }^{108}$ Natural polymeric nanoparticles, especially chitosan-based nanoparticles, because of their potential in hydrogel formation are suitable drug delivery systems for targeted delivery of water-soluble agents, peptides, proteins, and oligonucleotides to skin organelles. Synthetic polymeric nanoparticles with the advantage of better purity properties and controlled drug release are suitable for the delivery of both hydrophilic and lipophilic agents. ${ }^{89}$ Nanocrystals have a unique characteristic as drug delivery systems, ie, approximately $100 \%$ drug loading capacity because they are formed from pure active pharmaceuticals. They are suitable for dermal delivery of practically insoluble drugs with low dissolution rates but they have more stability problems such as flocculation and agglomeration which can restrict its application. This issue could be resolved by the use of nanosuspension stabilizers. ${ }^{109}$ The selection of suitable nanocarrier for topical delivery purposes is highly dependent on the aim of the study such as permeation enhancement (transdermal delivery) or targeted delivery to skin organelles and the nature of active pharmaceuticals that could be encapsulated. For topical delivery purposes, the compatibility of nanocarriers nature with skin structure should be considered.

\section{Acknowledgment}

Our special thanks go to Hassan Khajehei for language editing the manuscript.

\section{Author Contributions}

P.G. and S.M. made substantial contributions to conception and design, acquisition of data, or analysis and interpretation of data; took part in drafting the article or revising it critically for important intellectual content; gave final approval of the version to be published; and agree to be accountable for all aspects of the work.

\section{Disclosure}

The authors declare that they have no conflict of interest in the present project.

\section{References}

1. Carazo E, Borrego-Sánchez A, García-Villén F, et al. Advanced inorganic nanosystems for skin drug delivery. Chemical Record. 2018;18:891-899. doi:10.1002/tcr.201700061 
2. Baroli B. Penetration of nanoparticles and nanomaterials in the skin: fiction or reality? J Pharm Sci. 2010;99(1):21-50. doi:10.1002/jps. 21817

3. Khandavilli S, Panchagnula R. Nanoemulsions as versatile formulations for paclitaxel delivery: peroral and dermal delivery studies in rats. J Investigative Dermatol. 2007;127(1):154-162. doi:10.1038/sj.jid.5700485

4. Ghasemiyeh P, Azadi A, Daneshamouz S, Heidari R, Azarpira N, Mohammadi-Samani S. Cyproterone acetate-loaded nanostructured lipid carriers: effect of particle size on skin penetration and follicular targeting. Pharm Dev Technol. 2019;24 (7):812-823. doi:10.1080/10837450.2019.1596133

5. Lauterbach A, Müller-Goymann CC. Comparison of rheological properties, follicular penetration, drug release, and permeation behavior of a novel topical drug delivery system and a conventional cream. Eur J Pharm Biopharm. 2014;88 (3):614-624. doi:10.1016/j.ejpb.2014.10.001

6. Neubert RH. Potentials of new nanocarriers for dermal and transdermal drug delivery. Eur j Pharm Biopharm. 2011;77(1):1-2. doi:10.1016/j.ejpb.2010.11.003

7. Patzelt A, Mak WC, Jung S, et al. Do nanoparticles have a future in dermal drug delivery? J Controlled Release. 2017; 246:174-182. doi:10.1016/j.jconrel.2016.09.015

8. Fang C-L, Aljuffali IA, Li Y-C, Fang J-Y. Delivery and targeting of nanoparticles into hair follicles. Ther Deliv. 2014;5 (9):991-1006. doi:10.4155/tde.14.61

9. Paudel KS, Milewski M, Swadley CL, Brogden NK, Ghosh P, Stinchcomb AL. Challenges and opportunities in dermal/transdermal delivery. Ther Deliv. 2010;1(1):109-131. doi:10.4155/tde.10.16

10. Giannos SA. Identifying present challenges to reliable future transdermal drug delivery products. Ther Deliv. 2015;6 (8):1033-1041. doi:10.4155/tde.15.62

11. Thiagarajan P. Nanoemulsions for drug delivery through different routes. Res Biotechnol. 2011;2:3.

12. Lovelyn C, Attama AA. Current state of nanoemulsions in drug delivery. J Biomater Nanobiotechnol. 2011;2(05):626. doi:10.42 36/jbnb.2011.225075

13. Abd E, Namjoshi S, Mohammed YH, Roberts MS, Grice JE. Synergistic skin penetration enhancer and nanoemulsion formulations promote the human epidermal permeation of caffeine and naproxen. J Pharm Sci. 2015.

14. Baspinar Y, Borchert -H-H. Penetration and release studies of positively and negatively charged nanoemulsions - is there a benefit of the positive charge? Int J Pharm. 2012;430 (12):247-252. doi:10.1016/j.ijpharm.2012.03.040

15. Hoeller S, Sperger A, Valenta C. Lecithin based nanoemulsions: a comparative study of the influence of non-ionic surfactants and the cationic phytosphingosine on physicochemical behaviour and skin permeation. Int J Pharm. 2009;370(12):181-186. doi:10.10 16/j.ijpharm.2008.11.014

16. Luesakul U, Puthong S, Sansanaphongpricha K, Muangsin N. Quaternized chitosan-coated nanoemulsions: a novel platform for improving the stability, anti-inflammatory, anti-cancer and transdermal properties of plai extract. Carbohydr Polym. 2020;230:115625. doi:10.1016/j.carbpol.2019.115625

17. Cilurzo F, Chiara Cristiano M, Di Marzio L, et al. Influence of the supramolecular micro-assembly of multiple emulsions on their biopharmaceutical features and in vivo therapeutic response. Curr Drug Targets. 2015;16(14):1612-1622. doi:10.2174/138945 011614151119124234

18. Shah P, Bhalodia D, Shelat P. Nanoemulsion: a pharmaceutical review. Systematic Rev Pharmacy. 2010;1(1):24. doi:10.4103/ 0975-8453.59509

19. Garcês A, Amaral M, Lobo JS, Silva A. Formulations based on solid lipid nanoparticles (SLN) and nanostructured lipid carriers (NLC) for cutaneous use: A review. Eur J Pharm Sci. 2017.
20. Ghasemiyeh P, Azadi A, Daneshamouz S, Samani SM. Cyproterone acetate-loaded solid lipid nanoparticles (SLNs) and nanostructured lipid carriers (NLCs): preparation and optimization. Trends Pharma Sci. 2017;3(4):275-286.

21. Arora R, Katiyar SS, Kushwah V, Jain S. Solid lipid nanoparticles and nanostructured lipid carrier-based nanotherapeutics in treatment of psoriasis: a comparative study. Expert Opin Drug Deliv. 2017;14(2):165-177. doi:10.1080/17425247.2017.1264386

22. Borgia SL, Regehly M, Sivaramakrishnan R, et al. Lipid nanoparticles for skin penetration enhancement - correlation to drug localization within the particle matrix as determined by fluorescence and paraelectric spectroscopy. $J$ Controlled Release. 2005;110(1):151-163. doi:10.1016/j.jconrel.2005.09.045

23. Pokharkar VB, Mendiratta C, Kyadarkunte AY, Bhosale SH, Barhate GA. Skin delivery aspects of benzoyl peroxide-loaded solid lipid nanoparticles for acne treatment. Ther Deliv. 2014;5 (6):635-652. doi:10.4155/tde.14.31

24. Chantaburanan T, Teeranachaideekul V, Chantasart D, Jintapattanakit A, Junyaprasert VB. Effect of binary solid lipid matrix of wax and triglyceride on lipid crystallinity, drug-lipid interaction and drug release of ibuprofen-loaded solid lipid nanoparticles (SLN) for dermal delivery. $J$ Colloid Interface Sci. 2017;504:247-256. doi:10.1016/j.jcis.2017.05.038

25. Fang J-Y, Fang C-L, Liu C-H, Su Y-H. Lipid nanoparticles as vehicles for topical psoralen delivery: solid lipid nanoparticles (SLN) versus nanostructured lipid carriers (NLC). Eur J Pharm Biopharm. 2008;70(2):633-640. doi:10.1016/j.ejpb.2008.05.008

26. Kelidari H, Saeedi M, Akbari J, et al. Formulation optimization and in vitro skin penetration of spironolactone loaded solid lipid nanoparticles. Colloids Surf B Biointerfaces. 2015;128:473-479. doi:10.1016/j.colsurfb.2015.02.046

27. Chen J, Wei N, Lopez-Garcia M, et al. Development and evaluation of resveratrol, Vitamin E, and epigallocatechin gallate loaded lipid nanoparticles for skin care applications. Eur J Pharm Biopharm. 2017;117:286-291. doi:10.1016/j.ejpb.2017.04.008

28. Jenning V, Gysler A, Schäfer-Korting M, Gohla SH. Vitamin A loaded solid lipid nanoparticles for topical use: occlusive properties and drug targeting to the upper skin. Eur J Pharm Biopharm. 2000;49(3):211-218. doi:10.1016/S0939-6411(99)000 75-2

29. Üner M, Wissing S, Yener G, Müller R. Skin moisturizing effect and skin penetration of ascorbyl palmitate entrapped in solid lipid nanoparticles (SLN) and nanostructured lipid carriers (NLC) incorporated into hydrogel. Die Pharmazie- Int J Pharm Sci. 2005;60(10):751-755.

30. Souto E, Almeida A, Müller R. Lipid nanoparticles $\left(\mathrm{SLN}^{\circledR}\right.$, $\mathrm{NLC}^{\circledR}$ ) for cutaneous drug delivery: structure, protection and skin effects. J Biomed Nanotechnol. 2007;3(4):317-331. doi:10. 1166/jbn.2007.049

31. Ghasemiyeh P, Mohammadi-Samani S. Solid lipid nanoparticles and nanostructured lipid carriers as novel drug delivery systems: applications, advantages and disadvantages. Res Pharm Sci. 2018;13(4):288. doi:10.4103/1735-5362.235156

32. Üner M, Karaman EF, Aydoğmuş Z. Solid lipid nanoparticles and nanostructured lipid carriers of loratadine for topical application: physicochemical stability and drug penetration through rat skin. Tropical J Pharm Res. 2014;13(5):653-660. doi:10.4314/tjpr. v13i5.1

33. Park J-H, Ban S-J, Ahmed T, et al. Development of DH-I-180-3 loaded lipid nanoparticle for photodynamic therapy. Int J Pharm. 2015;491(12):393-401. doi:10.1016/j.ijpharm.2015.07.002

34. Ahmadnia S, Moazeni M, Mohammadi-Samani S, Oryan A. In vivo evaluation of the efficacy of albendazole sulfoxide and albendazole sulfoxide loaded solid lipid nanoparticles against hydatid cyst. Exp Parasitol. 2013;135(2):314-319. doi:10.1016/ j.exppara.2013.07.017 
35. Liu J, Hu W, Chen H, Ni Q, Xu H, Yang X. Isotretinoin-loaded solid lipid nanoparticles with skin targeting for topical delivery. Int J Pharm. 2007;328(2):191-195. doi:10.1016/j.ijpharm.2006.08.007

36. Pardeike J, Schwabe K, Müller RH. Influence of nanostructured lipid carriers (NLC) on the physical properties of the Cutanova Nanorepair Q10 cream and the in vivo skin hydration effect. Int $J$ Pharm. 2010;396(12):166-173. doi:10.1016/j.ijpharm.2010.06.007

37. Zoubari G, Staufenbiel S, Volz P, Alexiev U, Bodmeier R. Effect of drug solubility and lipid carrier on drug release from lipid nanoparticles for dermal delivery. Eur $J$ Pharm Biopharm. 2017;110:39-46. doi:10.1016/j.ejpb.2016.10.021

38. Müller RH, Radtke M, Wissing SA. Solid lipid nanoparticles (SLN) and nanostructured lipid carriers (NLC) in cosmetic and dermatological preparations. Adv Drug Deliv Rev. 2002;54: S131S55. doi:10.1016/S0169-409X(02)00118-7

39. Küchler S, Radowski MR, Blaschke T, et al. Nanoparticles for skin penetration enhancement - a comparison of a dendritic coremultishell-nanotransporter and solid lipid nanoparticles. Eur $J$ Pharm Biopharm. 2009;71(2):243-250. doi:10.1016/j.ejpb.20 08.08.019

40. Štecová J, Mehnert W, Blaschke T, et al. Cyproterone acetate loading to lipid nanoparticles for topical acne treatment: particle characterisation and skin uptake. Pharm Res. 2007;24 (5):991-1000. doi:10.1007/s11095-006-9225-9

41. Ribeiro LN, Breitkreitz MC, Guilherme VA, et al. Natural lipids-based NLC containing lidocaine: from pre-formulation to in vivo studies. Eur $J$ Pharm Sci. 2017;106:102-112. doi:10.1016/j.ejps.2017.05.060

42. Schwarz JC, Baisaeng N, Hoppel M, Löw M, Keck CM, Valenta C. Ultra-small NLC for improved dermal delivery of coenzyme Q10. Int J Pharm. 2013;447(12):213-217. doi:10. 1016/j.jpharm.2013.02.037

43. Patzelt A, Richter H, Knorr F, et al. Selective follicular targeting by modification of the particle sizes. $J$ Controlled Release. 2011;150(1):45-48. doi:10.1016/j.jconrel.2010.11.015

44. Ricci M, Puglia C, Bonina F, Giovanni CD, Giovagnoli S, Rossi C. Evaluation of indomethacin percutaneous absorption from nanostructured lipid carriers (NLC): in vitro and in vivo studies. J Pharm Sci. 2005;94(5):1149-1159. doi:10.1002/jps.20 335

45. Müller R, Petersen R, Hommoss A, Pardeike J. Nanostructured lipid carriers (NLC) in cosmetic dermal products. Adv Drug Deliv Rev. 2007;59(6):522-530. doi:10.1016/j.addr.2007.04.012

46. Sala M, Diab R, Elaissari A, Fessi H. Lipid nanocarriers as skin drug delivery systems: properties, mechanisms of skin interactions and medical applications. Int J Pharm. 2018;535(12):1-17. doi:10.1016/j.ijpharm.2017.10.046

47. El Maghraby GM, Williams AC, Barry BW. Can drug-bearing liposomes penetrate intact skin? J Pharmacy Pharmacol. 2006;58 (4):415-429. doi:10.1211/jpp.58.4.0001

48. Shah SM, Ashtikar M, Jain AS, et al. LeciPlex, invasomes, and liposomes: a skin penetration study. Int J Pharm. 2015;490 (12):391-403. doi:10.1016/j.ijpharm.2015.05.042

49. Egbaria K, Ramachandran C, Weiner N. Topical delivery of ciclosporin: evaluation of various formulations using in vitro diffusion studies in hairless mouse skin. Skin Pharmacol Physiol. 1990;3(1):21-28.

50. Lieb LM, Ramachandran C, Egbaria K, Weiner N. Topical delivery enhancement with multilamellar liposomes into pilosebaceous units: I. In vitro evaluation using fluorescent techniques with the hamster ear model. $J$ Investigative Dermatol. 1992;99 (1):108-113. doi:10.1111/1523-1747.ep12611886

51. Di Francesco M, Primavera R, Fiorito S, et al. Acronychiabaueri analogue derivative-loaded ultradeformable vesicles: physicochemical characterization and potential applications. Planta Med. 2017;83(05):482-491. doi:10.1055/s-0042-112225
52. Cristiano MC, Froiio F, Spaccapelo R, et al. Sulforaphane-loaded ultradeformable vesicles as a potential natural nanomedicine for the treatment of skin cancer diseases. Pharmaceutics. 2020;12 (1):6. doi:10.3390/pharmaceutics 12010006

53. Paolino D, Celia C, Trapasso E, Cilurzo F, Fresta M. Paclitaxelloaded ethosomes ${ }^{\circledR}$ : potential treatment of squamous cell carcinoma, a malignant transformation of actinic keratoses. Eur J Pharm Biopharm. 2012;81(1):102-112.

54. Kato A, Ishibashi Y, Miyake Y. Effect of egg yolk lecithin on transdermal delivery of bunazosin hydrochloride. $J$ Pharmacy Pharmacol. 1987;39(5):399-400. doi:10.1111/j.2042-7158.1987. tb03407.x

55. Sakdiset P, Kitao Y, Todo H, Sugibayashi K. High-throughput screening of potential skin penetration-enhancers using stratum corneum lipid liposomes: preliminary evaluation for different concentrations of ethanol. J Pharm. 2017;2017.

56. Duangjit S, Opanasopit P, Rojanarata $\mathrm{T}$, Ngawhirunpat $\mathrm{T}$. Characterization and in vitro skin permeation of meloxicam-loaded liposomes versus transfersomes. J Drug Deliv. 2011;2011.

57. Celia C, Cilurzo F, Trapasso E, Cosco D, Fresta M, Paolino D. Ethosomes $^{\circledR}$ and transfersomes ${ }^{\circledR}$ containing linoleic acid: physicochemical and technological features of topical drug delivery carriers for the potential treatment of melasma disorders. Biomed Microdevices. 2012;14(1):119-130. doi:10.1007/s10544-011-9590-y

58. Paolino D, Cosco D, Cilurzo F, et al. Improved in vitro and in vivo collagen biosynthesis by asiaticoside-loaded ultradeformable vesicles. J Controlled Release. 2012;162(1):143-151. doi:10. 1016/j.jconrel.2012.05.050

59. Choi M, Maibach H. Liposomes and niosomes as topical drug delivery systems. Skin Pharmacol Physiol. 2005;18(5):209-219. doi:10.1159/000086666

60. Schreier H, Bouwstra J. Liposomes and niosomes as topical drug carriers: dermal and transdermal drug delivery. $J$ Controlled Release. 1994;30(1):1-15. doi:10.1016/0168-3659(94)90039-6

61. Guterres SS, Alves MP, Pohlmann AR. Polymeric nanoparticles, nanospheres and nanocapsules, for cutaneous applications. Drug Target Insights. 2007;2:117739280700200002.

62. Manconi M, Sinico C, Valenti D, Loy G, Fadda AM. Niosomes as carriers for tretinoin. I. Preparation and properties. Int J Pharm. 2002;234(12):237-248. doi:10.1016/S0378-5173(01)00971-1

63. Park H, Park H, Na K. Dual Propionibacterium acnes therapy using skin penetration-enhanced liposomes loaded with a photosensitizer and an antibiotic. $J$ Porphyr Phthalocyanines. 2015;19(08):956-966. doi:10.1142/S1088424615500686

64. Verma D, Verma S, Blume G, Fahr A. Liposomes increase skin penetration of entrapped and non-entrapped hydrophilic substances into human skin: a skin penetration and confocal laser scanning microscopy study. Eur J Pharm Biopharm. 2003;55 (3):271-277. doi:10.1016/S0939-6411(03)00021-3

65. Balakrishnan P, Shanmugam S, Lee WS, et al. Formulation and in vitro assessment of minoxidil niosomes for enhanced skin delivery. Int J Pharm. 2009;377(12):1-8. doi:10.1016/j.ijpharm.2009.04.020

66. Tavano L, Picci N, Ioele G, Muzzalupo R. Tetracycline-niosomes versus tetracycline hydrochlo-ride-niosomes: how to modulate encapsulation and percutaneous permeation properties. J Drug. 2017;1(2):1-6.

67. Muzzalupo R, Pérez L, Pinazo A, Tavano L. Pharmaceutical versatility of cationic niosomes derived from amino acid-based surfactants: skin penetration behavior and controlled drug release. Int J Pharm. 2017;529(12):245-252. doi:10.1016/j.ijpharm.2017.06.083

68. Bragagni M, Scozzafava A, Mastrolorenzo A, Supuran CT, Mura P. Development and ex vivo evaluation of 5-aminolevulinic acid-loaded niosomal formulations for topical photodynamic therapy. Int $J$ Pharm. 2015;494(1):258-263. doi:10.1016/j.ijpharm.2015.08.036 
69. El-Menshawe SF, Hussein AK. Formulation and evaluation of meloxicam niosomes as vesicular carriers for enhanced skin delivery. Pharm Dev Technol. 2013;18(4):779-786. doi:10.3109/ 10837450.2011.598166

70. Fang J-Y, Yu S-Y, Wu P-C, Huang Y-B, Tsai Y-H. In vitro skin permeation of estradiol from various proniosome formulations. Int J Pharm. 2001;215(12):91-99. doi:10.1016/S0378-5173(00) 00669-4

71. Eid RK, Essa EA, El Maghraby GM. Essential oils in niosomes for enhanced transdermal delivery of felodipine. Pharm Dev Technol. 2018;1-9.

72. Junyaprasert VB, Singhsa P, Suksiriworapong J, Chantasart D. Physicochemical properties and skin permeation of Span 60/ Tween 60 niosomes of ellagic acid. Int J Pharm. 2012;423 (2):303-311. doi:10.1016/j.ijpharm.2011.11.032

73. Manconi M, Sinico C, Valenti D, Lai F, Fadda AM. Niosomes as carriers for tretinoin: III. A study into the in vitro cutaneous delivery of vesicle-incorporated tretinoin. Int J Pharm. 2006;311 (12):11-19. doi:10.1016/j.ijpharm.2005.11.045

74. Amoabediny G, Haghiralsadat F, Naderinezhad S, et al. Overview of preparation methods of polymeric and lipid-based (niosome, solid lipid, liposome) nanoparticles: a comprehensive review. Int Jo Polymeric Materials Polymeric Biomaterials. 2018;67(6):383-400. doi:10.1080/ 00914037.2017 .1332623

75. Fang J-Y, Hong C-T, Chiu W-T, Wang -Y-Y. Effect of liposomes and niosomes on skin permeation of enoxacin. Int J Pharm. 2001;219(12):61-72. doi:10.1016/S0378-5173(01)00627-5

76. Negi P, Aggarwal M, Sharma G, et al. Niosome-based hydrogel of resveratrol for topical applications: an effective therapy for pain related disorder(s). Biomed Pharmacother. 2017;88: 480-487. doi:10.1016/j.biopha.2017.01.083

77. Patel V, Sharma OP, Mehta T. Nanocrystal: a novel approach to overcome skin barriers for improved topical drug delivery. Expert Opin Drug Deliv. 2018;15(4):351-368. doi:10.1080/17425247. 2018.1444025

78. Pireddu R, Caddeo C, Valenti D, et al. Diclofenac acid nanocrystals as an effective strategy to reduce in vivo skin inflammation by improving dermal drug bioavailability. Colloids Surf B Biointerfaces. 2016;143:64-70. doi:10.1016/j.colsurfb.2016.03.026

79. Müller RH, Gohla S, Keck CM. State of the art of nanocrystals special features, production, nanotoxicology aspects and intracellular delivery. Eur J Pharm Biopharm. 2011;78(1):1-9. doi:10.1016/j.ejpb.2011.01.007

80. Shegokar R. What nanocrystals can offer to cosmetic and dermal formulations. Nanobiomater Galenic Formulations Cosmetics. 2016;69-91.

81. Mitri K, Shegokar R, Gohla S, Anselmi C, Müller RH. Lutein nanocrystals as antioxidant formulation for oral and dermal delivery. Int $J$ Pharm. 2011;420(1):141-146. doi:10.1016/j. ijpharm.2011.08.026

82. Döge N, Hönzke S, Schumacher F, et al. Ethyl cellulose nanocarriers and nanocrystals differentially deliver dexamethasone into intact, tape-stripped or sodium lauryl sulfate-exposed ex vivo human skin-assessment by intradermal microdialysis and extraction from the different skin layers. J Controlled Release. 2016;242:25-34. doi:10.1016/j. jconrel.2016.07.009

83. Pyo SM, Hespeler D, Keck CM, Müller RH. Dermal miconazole nitrate nanocrystals-formulation development, increased antifungal efficacy \& skin penetration. Int J Pharm. 2017;531 (1):350-359. doi:10.1016/j.ijpharm.2017.08.108

84. Pyo SM, Meinke M, Keck CM, Müller RH. Rutin - increased antioxidant activity and skin penetration by nanocrystal technology (smartCrystals). Cosmetics. 2016;3(1):9. doi:10.3390/cosmetics 3010009
85. Yoshioka C, Ito Y, Nagai N. Enhanced percutaneous absorption of cilostazol nanocrystals using aqueous gel patch systems and clarification of the absorption mechanism. Exp Ther Med. 2018;15 (4):3501-3508. doi:10.3892/etm.2018.5820

86. Luppi B, Cerchiara T, Bigucci F, Basile R, Zecchi V. Polymeric nanoparticles composed of fatty acids and polyvinylalcohol for topical application of sunscreens. $J$ Pharmacy Pharmacol. 2004;56(3):407-411. doi:10.1211/0022357022926

87. Chaves LL, Silveri A, Vieira AC, et al. pH-responsive chitosan based hydrogels affect the release of dapsone: design, set-up, and physicochemical characterization. Int $J$ Biol Macromol. 2019;133:1268-1279. doi:10.1016/j.ijbiomac.2019.04.178

88. Ghasemiyeh P, Mohammadi-Samani S. Hydrogels as drug delivery systems; pros and cons. Trends Pharma Sci. 2019;5 (1):7-24.

89. Zhang Z, Tsai PC, Ramezanli T, Michniak-Kohn BB. Polymeric nanoparticles-based topical delivery systems for the treatment of dermatological diseases. Wiley Interdiscip Rev Nanomed Nanobiotechnol. 2013;5(3):205-218. doi:10.1002/ wnan. 1211

90. Chellappan DK, Yee NJ, Kaur Ambar Jeet Singh BJ, Panneerselvam J, Madheswaran T, Chellian J, et al. Formulation and characterization of glibenclamide and quercetin-loaded chitosan nanogels targeting skin permeation. Ther Deliv. 2019;10 (5):281-293. doi:10.4155/tde-2019-0019

91. Coviello T, Trotta A, Marianecci C, et al. Gel-embedded niosomes: preparation, characterization and release studies of a new system for topical drug delivery. Colloids Surf B Biointerfaces. 2015;125:291-299. doi:10.1016/j.colsurfb.2014.10.060

92. Dave K, Krishna Venuganti VV. Dendritic polymers for dermal drug delivery. Ther Deliv. 2017;8(12):1077-1096. doi:10.4155/ tde-2017-0091

93. Batheja P, Sheihet L, Kohn J, Singer AJ, Michniak-Kohn B. Topical drug delivery by a polymeric nanosphere gel: formulation optimization and in vitro and in vivo skin distribution studies. $J$ Controlled Release. 2011;149(2):159-167. doi:10.1016/j. jconrel.2010.10.005

94. Sheihet L, Chandra P, Batheja P, Devore D, Kohn J, Michniak B. Tyrosine-derived nanospheres for enhanced topical skin penetration. Int J Pharm. 2008;350(12):312-319. doi:10.1016/j. ijpharm.2007.08.022

95. Rodríguez-Cruz IM, Merino V, Merino M, Díez O, Nácher A, Quintanar-Guerrero D. Polymeric nanospheres as strategy to increase the amount of triclosan retained in the skin: passive diffusion vs Iontophoresis. J Microencapsulation. 2013;30 (1):72-80. doi:10.3109/02652048.2012.700956

96. Alvarez-Román R, Naik A, Kalia Y, Guy RH, Fessi H. Skin penetration and distribution of polymeric nanoparticles. J Controlled Release. 2004;99(1):53-62. doi:10.1016/j.jconrel.20 04.06.015

97. Balzus B, Sahle FF, Hönzke S, et al. Formulation and ex vivo evaluation of polymeric nanoparticles for controlled delivery of corticosteroids to the skin and the corneal epithelium. Eur J Pharm Biopharm. 2017;115:122-130. doi:10.1016/j.ejpb.2017. 02.001

98. Shah PP, Desai PR, Patel AR, Singh MS. Skin permeating nanogel for the cutaneous co-delivery of two anti-inflammatory drugs. Biomaterials. 2012;33(5):1607-1617. doi:10.1016/j.biomaterials. 2011.11.011

99. Todo H, Kimura E, Yasuno H, et al. Permeation pathway of macromolecules and nanospheres through skin. Biol Pharm Bull. 2010;33(8):1394-1399. doi:10.1248/bpb.33.1394

100. Lee P-W, Peng S-F, Su C-J, et al. The use of biodegradable polymeric nanoparticles in combination with a low-pressure gene gun for transdermal DNA delivery. Biomaterials. 2008;29 (6):742-751. doi:10.1016/j.biomaterials.2007.10.034 
101. Pivetta TP, Simões S, Araújo MM, Carvalho T, Arruda C, Marcato PD. Development of nanoparticles from natural lipids for topical delivery of thymol: investigation of its anti-inflammatory properties. Colloids Surf B Biointerfaces. 2018;164:281-290. doi:10.1016/j.colsurfb.2018.01.053

102. Mandawgade SD, Patravale VB. Development of SLNs from natural lipids: application to topical delivery of tretinoin Int $J$ Pharm. 2008;363(12):132-138. doi:10.1016/j.ijpharm.20 08.06.028

103. Pardeike J, Hommoss A, Müller RH. Lipid nanoparticles (SLN, NLC) in cosmetic and pharmaceutical dermal products. Int J Pharm. 2009;366(12):170-184. doi:10.1016/j.ijpharm.20 08.10 .003

104. Mu L, Sprando RL. Application of nanotechnology in cosmetics. Pharm Res. 2010;27(8):1746-1749. doi:10.1007/s11095-0100139-1

105. Babaei S, Ghanbarzadeh S, Adib Z, Kouhsoltani M, Davaran S, Hamishehkar H. Enhanced skin penetration of lidocaine through encapsulation into nanoethosomes and nanostructured lipid carriers: a comparative study. Die Pharmazie- Int J Pharm Sci. 2016;71(5):247-251.
106. Wolf M, Klang V, Stojcic T, Fuchs C, Wolzt M, Valenta C. NLC versus nanoemulsions: effect on physiological skin parameters during regular in vivo application and impact on drug penetration. Int J Pharm. 2018;549(12):343-351. doi:10.1016/j. ijpharm.2018.08.007

107. Aly UF, Abou-Taleb HA, Abdellatif AA, Tolba NS. Formulation and evaluation of simvastatin polymeric nanoparticles loaded in hydrogel for optimum wound healing purpose. Drug Des Devel Ther. 2019;13:1567. doi:10.2147/DDDT.S198413

108. Mao K-L, Fan Z-L, Yuan J-D, et al. Skin-penetrating polymeric nanoparticles incorporated in silk fibroin hydrogel for topical delivery of curcumin to improve its therapeutic effect on psoriasis mouse model. Colloids Surf B Biointerfaces. 2017;160:704-714. doi:10.1016/j.colsurfb.2017.10.029

109. Patel V, Sharma OP, Mehta TA. Impact of process parameters on particle size involved in media milling technique used for preparing clotrimazole nanocrystals for the management of cutaneous candidiasis. AAPS Pharm Sci Tech. 2019;20(5):175. doi:10.1208/ s12249-019-1368-1

\section{Publish your work in this journal}

Drug Design, Development and Therapy is an international, peerreviewed open-access journal that spans the spectrum of drug design and development through to clinical applications. Clinical outcomes, patient safety, and programs for the development and effective, safe, and sustained use of medicines are a feature of the journal, which has also been accepted for indexing on PubMed Central. The manuscript management system is completely online and includes a very quick and fair peer-review system, which is all easy to use. Visit http://www. dovepress.com/testimonials.php to read real quotes from published authors. 